\title{
Lifeworks
}

\section{Looking death in the face}

Ah! Seigneur! donnez-moi la force et le courage De contempler mon cœur et mon corps sans dégoût.

- Charles Baudelaire, Les Fleurs du mal (1857)

Tmages of the dead have always been Lused in art to shock, horrify, sadden and awe. Occasionally, such images also manage to isolate a strange beauty that quietly reminds us of the delicate power of life. Such beauty is evident in the work of photographer Jack Burman exhibited at the Clint Roenisch Gallery in Toronto from May 13 to June 20, 2004.

The 12 large-scale (up to almost 50" $\times 70$ ") colour photographs in this collection document preserved body parts that Burman was permitted to photograph in medical museums and anatomy labs, located mainly in Eastern Europe and South America. His images of dismembered heads and hands and disembodied hearts confront us with our private fears of death and mutilation. However, if we are able to overcome our initial revulsion toward their content, we may find in these photographs an unusual beauty.

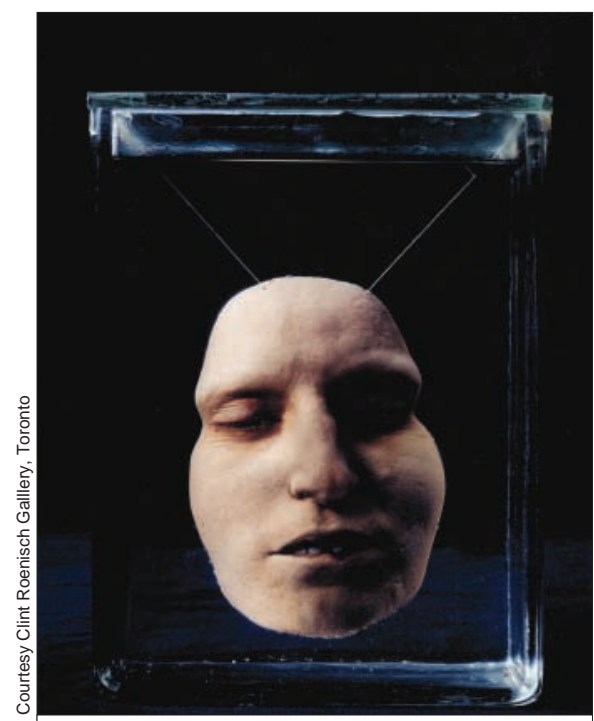

Jack Burman (2003). USA \#5. Colour photograph. Permission granted by Mütter Museum of College of Physicians of Philadelphia
Writing about photographs of murder scenes taken in early 20th-century Paris, art historian Eugenia Parry states, "Through the pictures, we enter a realm of unfathomable strangeness, an experience as old as humanity itself, but one essential to integrating the incomprehensibility of what links death to our own humanity." "This statement can easily be applied to Burman's photographs. It can be unnerving to see a body separated from its living essence, the quality that is often called the soul. It can be even more unsettling to see the body detached, dismembered or dissected into isolated parts. In Burman's photographs, a once-animate subject is frozen in time both by formaldehyde and by the artifice of the photographer's lighting and presentation.

As physicians, each of us remembers the moment in medical school when we filed into the anatomy lab and stood, filled with fear, anxiety and the thrill of the forbidden as our professor pulled back the sheet to reveal our first cadaver. This uncomfortable excitement soon receded as we became more accustomed to dissecting preserved organs and limbs. For some of us this eventually led to moments in the operating room, and perhaps even to holding a beating heart in our hands. Most visitors to the exhibition will not have been desensitized by the familiarity acquired during medical training, and will feel uncomfortable, conflicting emotions when they look at Burman's photographs. Here are images that create a mixture of wonder and revulsion. A slice of head, including only the eyes and nose, occupies a Plexiglas cube on a table covered in blue velvet, suggesting someone lying in the kind of box into which a magician inserts his swords. The eyes are partly closed, looking down, as if seeking the rest of their body. A thin slice of face appears suspended by strings in a square box of fluid, bubbles of air clinging to its edges, as if it were continuing to exhale. The severed head of a bearded man looks so vividly lifelike that it is shocking to discover that below the head there is no body; the effect almost makes us wonder if it is possible to be alive without one. There is an unsettling insinuation of life in these photos of death. Their persistent humanity demands that we contemplate them, rather than turn away in disgust.

\section{Jonah Samson \\ Family Physician \\ Vancouver, BC}

\section{Reference}

1. Parry E. They say I and I: and mean: anybody. In: Witkin JP, editor. Harms way: lust \& madness, mur der of mayhem. New Mexico: Twin Palms, 1994. 